УСТИНКИН Сергей Васильевич - доктор исторических наук, профессор, директор международной междисциплинарной научно-исследовательской лаборатории «Изучение мировых и региональных социально-политических процессов» НГЛУ им. Н.А. Добролюбова (603155, г. Нижний Новгород, ул. Минина, д. 31а); директор Приволжского филиала ФНИСЦ РАН (603000, г. Нижний Новгород, пер. Холодный,д. 48; sv.ustinkin@gmail.com)

МОРОЗОВА Наталья Михайловна - кандидат политических наук, доцент кафедры международных отношений и мировых политических процессов, младший научный сотрудник международной междисииплинарной научно-исследовательской лаборатории «Изучение мировых и региональных социально-политических процессов» НГЛУ им. Н.А. Добролюбова (603155, г. Нижний Новгород, ул. Минина, д. 31a); заместитель директора Приволжсккого филиала ФНИСЦ РАН (603000. Нижний Новгород, пер. Холодный, д. 48; 4379037@gmail.com)

\title{
ОЦЕНКА СИСТЕМЫ УПРАВЛЕНИЯ ЭТНОКОНФЕССИОНАЛЬНЫМИ ОТНОШЕНИЯМИ В НИЖЕГОРОДСКОЙ ОБЛАСТИ
}

Аннотация. Предоставлен анализ системы управления межнациональными и конфессиональными процессами в Нижегородской области. Основываясь на данных социологических исследований, авторы приходят к выводу о том, что благодаря комплексной работе региональных властей, силовых структур, лидеров традиционных конфессий, диаспор и национальных общин постепенно меняется в позитивную сторону отношение общества к мигрантам и этническим группам, проживающим на территории Нижегородской области. В статье приводятся рекомендации по совершенствованию сложившей системы управления.

Ключевые слова: этноконфессиональные отношения, межнациональные отношения, этническая группа, диаспора, власть

$\mathrm{P}$ азнообразие и уникальность этноконфессионального состава России, выступает серьезным внутриполитическим и внешнеполитическим ресурсом государства, что отражено в Конституции страны 1 . На территории России проживает более 190 этнических групп, включающие и коренные малые, и коренные автохтонные народы. При этом доля респондентов, участвующих во Всероссийской переписи 2010 г. и идентифицирующих себя как «русские», составила $80,9 \%^{2}$. В Федеральном статистическом обследовании «Социальнодемографического обследования (микроперепись населения)», осуществленном в 2015 г. участие приняли 164 национальные группы. Сокращение числа народов, участвующих в обследовании связано с его спецификой и выборочным характером опроса ${ }^{3}$.

Разнообразие этнического состава в контексте исторического развития государства способствовало усилению специфических культурных традиций

\footnotetext{
${ }^{1}$ Конституция РФ. Доступ: https://rg.ru/2020/07/04/konstituciya-site-dok.html (Дата обращения 02.12.2020)

2 Всероссийская перепись населения 2010. Т.4. Национальный состав и владение языками, гражданство. Доступ: https://rosstat.gov.ru/free_doc/new_site/perepis2010/croc/perepis_ itogil612.htm (Дата обращения: 03.12.2020);

3 Доклад об основных итогах Федерального статистического обследования «Социальнодемографическое обследование (микроперепись населения) 2015 года». 2016 г. Доступ: https://rosstat.gov.ru/free_doc/new_site/population/demo/micro-perepis/finish/doklad. pdf(Дата обращения: 03.12.2020)
} 
народов и верований. Традиционными религиями на территории России рассматриваются православие, ислам, старообрядчество, язычество, буддизм, которые по своей структуре не являются однородными, подразделяясь на направления, принадлежность к церковной иерархии и т.д. [Желтов 2017: 5]. Таким образом, конфессиональная структура населения выглядит весьма сложно. Самая распространенная религия в России - православие. По данным ВЦИОМ в 2019 г. православными себя определило $63 \%$ опрошенных ${ }^{1}$, а Фонда общественного мнения- 65\%2. Отметим, что в 2007 г. исследования ВЦИОМ показали $75 \%$ респондентов, относивших себя к православию ${ }^{3}$. По данным же исследовательского центра Pew Research Center, в 2017 г. на территории России доля православных составляла $71 \%$, мусульман - $10 \%$, и относящих себя к другим религиям $-4 \% 4$.

Что же касается мусульман, проживающих на территории страны, то оценки их количества расходятся. О 10 \% мусульман говорил Зорин В.Ю., оценивая данные переписи населения 2002 г. ${ }^{5}$ По данным ВЦИОМ в 2019 г. доля мусульман составляет $5 \% 6$. Исследователи Финансового университета при Правительстве РФ Идрисова М.Ш. и Кочоян В.Г., опираясь на результаты исследования ФОМ, опубликованные в 2000 г. и данные Духовного управления мусульман 2014 г, зафиксировали рост доли мусульман с 5,5 до $16 \% 7$. Глава совета муфтиев России и председатель президиума Духовного управления мусульман европейской части России Гайнутдин Р. И., выступая в Госдуме на научно-практической конференции «История ислама в России: традиции патриотизма и сосуществования» в 2019 г., отметил, что «через полтора десятка лет до 30 \% населения России будут составлять мусульмане» 8 .

1 ВЦИОМ. Аналитический обзор. Православная вера и таинство крещения. Доступ: https://wciom.ru/analytical-reviews/analiticheskii-obzor/pravoslavnaya-vera-i-tainstvo-kreshheniya (Дата обращения 03.12.2020)

2 ФОМ. Отношение к РПЦ и патриарху. Доступ: https://fom.ru/TSennosti/14178(Дата обращения: 03.12.2020)

3 ВЦИОМ. Аналитический обзор. Религия в нашей жизни. Доступ: https://wciom.ru/ analytical-reviews/analiticheskii-obzor/religiya-v-nashej-zhizni(Дата обращения: 03.12.2020)

4 PewResearchCenter. Религия и национальная принадлежность в Центральной и Восточной Европе. Мировая динамика: факты, цифры, тенденции. Доступ: https://www. pewresearch.org/wp-content/uploads/sites/7/2017/05/CEUP-Overview-Russian-FOR-WEB.pdf (Дата обращения: 04.12.2020)

5 Позволяют ли данные Всероссийской переписи населения установить численность мусульман в стране? // Информационно-аналитический центр СОВА. Доступ: https://www. sova-center.ru/religion/discussions/how-many/2003/11/d1280/ (дата обращения 30.11.2020)

6 ВЦИОМ. Аналитический обзор. Православная вера и таинство крещения. Доступ: https://wciom.ru/analytical-reviews/analiticheskii-obzor/pravoslavnaya-vera-i-tainstvo-kreshheniya (Дата обращения 03.12.2020)

7 Идрисова М.Ш. и Кочоян В.Г. Исламизация России - вопрос времени? Доступ: http://www.fa.ru/science/studevents/mnsk/V/\% D $0 \% 9$ D\% D $0 \%$ B $0 \%$ D $1 \%$ $83 \% \mathrm{D} 1 \% 87 \% \mathrm{D} 0 \% \mathrm{BD} \% \mathrm{D} 0 \% \mathrm{BE} \% \mathrm{D} 0 \% \mathrm{~B} 5 \% 20 \% \mathrm{D} 0 \% \mathrm{BD} \% \mathrm{D} 0 \% \mathrm{~B} 0 \% \mathrm{D} 0 \% \mathrm{BF} \% \mathrm{D} 1 \% 80 \% \mathrm{D} 0 \% \mathrm{~B} 0$ $\% \mathrm{D} 0 \% \mathrm{~B} 2 \% \mathrm{D} 0 \% \mathrm{BB} \% \mathrm{D} 0 \% \mathrm{~B} 5 \% \mathrm{D} 0 \% \mathrm{BD} \% \mathrm{D} 0 \% \mathrm{~B} 8 \% \mathrm{D} 0 \% \mathrm{~B} 5 \% 20 \% \mathrm{D} 1 \% 81 \% \mathrm{D} 0 \% \mathrm{BE} \% \mathrm{D} 1 \% 86 \%$ D0\%B8\%D0\%BE\% D0\%BB\%D0\%BE\%D0\%B3\%D0\%B8\%D0\%B8\%20\%D0\%B8\%20\%D0\%BF $\% \mathrm{D} 0 \% \mathrm{BE} \% \mathrm{D} 0 \% \mathrm{BB} \% \mathrm{D} 0 \% \mathrm{~B} 8 \% \mathrm{D} 1 \% 82 \% \mathrm{D} 0 \% \mathrm{BE} \% \mathrm{D} 0 \% \mathrm{BB} \% \mathrm{D} 0 \% \mathrm{BE} \% \mathrm{D} 0 \% \mathrm{~B} 3 \% \mathrm{D} 0 \% \mathrm{~B} 8 \% \mathrm{D} 0 \%$ B8/\%D0\%A2\%D0\%B5\%D0\%BE\%D1\%80\%D0\%B5\%D1\%82\%D0\%B8\%D1\%87\%D0\%B5\%D1 $\% 81 \% \mathrm{D} 0 \% \mathrm{BA} \% \mathrm{D} 0 \% \mathrm{~B} 0 \% \mathrm{D} 1 \% 8 \mathrm{~F} \% 20 \% \mathrm{D} 1 \% 81 \% \mathrm{D} 0 \% \mathrm{BE} \% \mathrm{D} 1 \% 86 \% \mathrm{D} 0 \% \mathrm{~B} 8 \% \mathrm{D} 0 \% \mathrm{BE} \% \mathrm{D} 0 \% \mathrm{~B}$ B\%D0\%BE\%D0\%B3\%D0\%B8\%D1\%8F/\%D0\%98\%D0\%B4\%D1\%80\%D0\%B8\%D1\%81\%D0\% BE\%D0\%B2\%D0\%B0\%20\%D0\%9C.\%D0\%A8.,\%20\%D0\%9A\%D0\%BE\%D1\%87\%D0\%BE\%D $1 \% 8 \mathrm{~F} \% \mathrm{D} 0 \% \mathrm{BD} \% 20 \% \mathrm{D} 0 \% 92 . \% \mathrm{D} 0 \% 93 . \mathrm{pdf}$ search=\%D0\%B8\%D1\%81\%D0\%BB\%D0\%B0\%D 0\%BC\%D0\%B8\%D0\%B7\% D0\%B0\%D1\%86\%D0\%B8\%D1\%8F (Дата обращения 03.12.2020)

8 Глава совета муфтиев предсказал рост доли мусульман в России. Доступ: https://www. rbc.ru/society/04/03/2019/5c7d312f9a794786546fa2de (Дата обращения 04.12.2020) 
Этноконфессиональный фактор, наслаиваясь на этнически мозаичную структуру населения, существенно осложняет работу по управлению этноконфессиональными отношениями в государстве. Это во многом связано, на наш взгляд, с тем, что конфессиональные группы, так же, как и этнические, основываются на определенном наборе ценностей. В условиях этноконфессионального разнообразия сформировался ряд моделей с уникальным набором ценностных установок, вобравших в себя и этнические, и религиозные ценности.

Несмотря на многовековую традицию проживания многочисленных этноконфессиональных групп на территории одного государства существует объективная потребность в системе управления этноконфессиональными процессами. Это связано и с внутренними противоречиями, которые периодически возникают между этническими и конфессиональными группами, но, в большей степени, с усилением внешнего фактора на степень консолидации населения многонационального российского государства.

Действие внешнего фактора выражается, во-первых, в интенсификации миграционных потоков, которые накладываются на этноконфессиональные процессы в России, усложняя их дополнительно, вызывая усиление напряженности. Во-вторых, стоит учитывать деятельность деструктивных религиозных организаций и внешнеполитических сил, целями которых являются усиление противоречий и раскол среди представителей традиционных религий, радикализация ислама, активизация групп населения по этническому признаку (этнонационализм) и т.д.

Необходимо отметить, что система управления, как на государственном, так и на региональном, уровне включает структуры, в компетенции которых вопросы межнационального взаимодействия, так и религиозные организации. В эту же систему оказываются включенными государственные структуры, занимающиеся разработкой и реализацией миграционной политики, силовые структуры.

На общегосударственном, федеральном уровне, межнациональные отношения оформлены в рамках Федерального агентства по делам национальностей. Организация работы данного ведомства, исходя из его структуры, носит проектный характер. Агентство осуществляет мониторинг и анализ ситуации в межнациональной сфере, реализует целевые и специальные программы и проекты, а также отвечает за профилактику экстремизма на национальной и религиозной форме. Данное агентство не имеет территориальных подразделений и в своей работе опирается на взаимодействие с подразделениями региональных органов власти и управления, ответственными за реализацию государственной национальной политики ${ }^{1}$.

С 2012 г. действует Совет по межнациональным отношениям при Президенте РФ, основные задачи и функции которого находятся в консультативно-совещательном поле ${ }^{2}$. Активно участвуют в вопросах реализации национальной политики общественные организации. Наиболее активно себя проявляет в последние годы Ассамблея народов России.

Непосредственной реализацией программ и проектов в рамках системы управления межнациональными и конфессиональными отношениями зани-

\footnotetext{
1 Положение о Федеральном агентстве по делам национальностей. Доступ: http://fadn. gov.ru/agency/polozhenie-ob-agentstve (Дата обращения: 28.11.2020)

2 Положение о Совете при Президенте Российской Федерации по межнациональным отношениям. Доступ: http://kremlin.ru/events/president/news/15577(Дата обращения: 28.11.2020)
} 
маются региональные структуры власти. В начале 2010-х гг. шла активная дискуссия о моделях реализации национальной политики в регионах. Выступая на Конгрессе народов России, прошедшем в Нижнем Новгороде в сентябре 2013 г. Зорин В.Ю. - член Совета при Президента РФ по межнациональным отношениям, Смирнова С.К., председатель Совета Ассамблеи народов России, единогласно отметили, что цели и задачи национальной политики должны быть едины во всех регионах, при этом конкретные механизмы их достижения должны вырабатываться с учетом исторических традиций развития субъектов ${ }^{1}$. Практика показывает, что по этому пути и пошли.

Не смотря на то, что $93 \%$ населения Нижегородской области - русские (по критерию «абсолютного большинства» одной этнической группы можно рассматривать его как моноэтничный), на ее территории проживает более 100 народов и этнических групп, что относит субъект федерации к многонациональным. Вторые по численности населения - татары $-1,3 \% 2$. Специфика этнического состава накладывает отпечаток на систему регионально власти: в Нижегородской области отсутствует специальное ведомство, занимающееся исключительно межнациональными вопросами [Бахлов, Бахлова 2018: 6 - 7]. Вопросы этноконфессионального характера находятся в компетенции Министерства внутренней, региональной и муниципальной политики.

В рамках Министерства функционирует отдел взаимодействия с национальными и религиозными объединениями, который занимается реализацией мероприятий в рамках межнациональной политики, поддерживает контакт с диаспорами, землячествами, национально-культурными общественными объединениями, которых в области зарегистрировано более 40, религиозными организациями. Деятельность данного отдела включает в себя мероприятия по мониторингу этноконфессиональной напряженности, создание рабочих групп «оперативного реагирования» в случае усиления напряжения или возникновении конфликта на этноконфессиональной почве, просветительские мероприятия и грантовую поддержку НКО.

При Губернаторе Нижегородской области действует Экспертноаналитический совет по проблемам социально-экономического и общественно-политического развития, который, среди прочих вопросов, отслеживает состояние этноконфессиональных отношений в регионе.

На уроне муниципалитетов (при главах района) осуществляют работу общественно-консультативные советы, в состав которых входят представители диаспор, землячеств, национально-культурных организаций и традиционных конфессий. Подобного рода открытые дискуссионные площадки позволяют представителям общин обсуждать наиболее острые вопросы и вырабатывать подходы к их решению. Кроме того, вовлеченность региональных властей в межконфессиональный и межнациональный диалог «ускоряет процесс взаимопонимания».

Антитеррористической деятельностью, выявлением радикальных и экстремистских настроений среди представителей диаспор и общин, занимаются и вышеперечисленные административные структуры власти, и силовые региональные ведомства. К компетенции последней также относится работа в области правонарушений с участием мигрантов.

1 В Нижнем Новгороде в одиннадцатый раз состоялся Конгресс народов России Доступ: http://www.ifregion.ru/article/f525f04a-1c49-11e3-98ca-001c140132d6 (Дата обращения 04.12.2020

2 Всероссийская перепись населения 2010. Т.4. Национальный состав и владение языками, гражданство. Доступ: https://rosstat.gov.ru/free_doc/new_site/perepis2010/croc/perepis itogi1612.htm (Дата обращения 03.12.2020 
Конфессиональными вопросами занимаются Нижегородская митрополия Русской православной церкви и Духовное управление мусульман Нижегородской области. Деятельность этих организаций нацелена на формирование межконфессионального мира и согласия. Кроме того, в межконфессиональных процессах участвуют представители иудаизма, католической церкви.

В структуре управления этноконфессиональными процессами в Нижегородской области особую роль играют диаспоры и национальные общины. В ряде случаев они занимаются и этническими, и конфессиональными вопросами (этнические группы, исповедующие ислам). Зачастую лидеры диаспор, являясь лидерами неформальными, обладают высокой степенью влияния и могут оперативно разрешать возникающие проблемы.

Таким образом, в регионе сложилась и весьма эффективно функционирует на протяжении последних $5-7$ лет система управления межнациональными и этноконфессиональными взаимодействиями. Точкой отсчета для нас в данном случае выступает 2013 г., который характеризовался усилением межнациональных противоречий и возникновением межэтнических конфликтов: Пугачев, Бирюлево - это самые яркие примеры. Даже «спокойная» Нижегородская область попала в федеральные новостные сводки с новостью о случившемся в декабре 2013 г. конфликте [Морозова, Устинкин 2016: 104 - 105].

Эскалация конфликта на межнациональной почве в тот период свидетельствовала, во-первых, об объективно существующем комплексе противоречий в обществе, во-вторых, отстранении власти от вопросов поддержания межнационального и этноконфессионального согласия.

Необходимо отметить, что с 2013 г. в Нижегородской области заметно активизировалась работа административных органов и в рамках, сначала разработки проекта Стратегии национальной политики, а затем его реализации осуществлялась планомерная деятельность по снижению уровня напряжения на межнациональной почве. Это дало свои плоды. В 2015 - 2017 гг. ФНИСЦ РАН проводилось исследование «Прогнозное моделирование межэтнических отношений в российских регионах (на основе анализа идентификационных стратегий диаспорных/земляческих групп)» (рук. А.В. Дмитриев), включающее в качестве методологического инструментария анализ медийного дискурса, фокус-группы с представителями диаспор и землячеств и экспертные интервью. Оно выявило весьма стабильную ситуацию в сфере межнационального взаимодействия, стремление диаспор и национальных общин сотрудничать с властью.

В контексте анализа системы управления межнациональными отношениями в регионе, на наш взгляд, необходимо отметить проблемы, затрудняющие ее работу и снижающие эффективность (по оценкам экспертов, принявших участие в опросе в 2017 г.).

Во-первых, отмечалось необходимость разграничения полномочий между профильными отделами Правительства региона и силовыми структурами. Так, по мнению экспертов, опросы экстремизма и терроризма должны в большей степени координироваться правоохранительными органами и силовыми структурами, которые должны оказывать поддержку Правительству.

Во-вторых, высокая загруженность специалистов и потребность в расширении структуры, которая бы занималась вопросами реализации национальной политики на территории региона (комитет, департамент).

Несмотря на объективно существующие проблемы, руководство региона смогло выстроить весьма эффективно функционирующую систему управления этноконфессиональными процессами, значительное внимание уделяя мониторингу напряженности на межнациональной почве (проводятся поквартальные исследования) и мероприятиям просветительского характера, 
работе со СМИ. На наш взгляд, в качестве примера того, что сложившаяся система является действенной, можно привести следующий: в связи с эскалацией конфликта в Нагорном Карабахе осенью 2020 г. серьезного усиления конфликта между армянской и азербайджанской диаспорами на территории Нижегородской области не отмечалось.

Положительным примером является и постепенное изменение отношения молодежи к мигрантам и этническим группам. Исследователями НГЛУ им. Н.А. Добролюбова совместно с Приволжским филиалом ФНИСЦ РАН осуществляется многолетнее исследование «Динамика ценностных ориентаций молодежи». Исследование проводится с 2005 г., и в 2014 гг. показатели отрицательного отношения были максимальными за весь период $(31,2 \%)$ (положительно относилось к мигрантам $(8,3 \%)$. В отношении представителей народов России молодые люди оказались более лояльными, но общая тенденция напряжения отразилась и в этом случае (12 \% высказались о положительном отношении, а 24,5 \% - об отрицательном). Замеры проводились в 2015 - 2016 гг., и также показали превышение отрицательных оценок над положительными. Только в 2019 г. картина изменилась: 16,2 \% опрошенной молодежи лояльно расположены к мигрантам, а 11,3\% - сохраняют негативное отношение. Что же касается отношения к народам России, то к ним положительно относятся 22,7 \%, а отрицательно - 9,1 \% [Современный мир... 2019: 190].

Таким образом, мы видим, что отношение молодежи к представителям национальных общин и диаспор постепенно меняется. Но делать вывод, что это явно выраженная тенденция, на наш взгляд, еще рано. Позитивные изменения в оценках стали, несомненно, результатом комплексной работы по управлению межнациональными отношениями и формированию «позитивного фона» в региональном обществе.

Но необходимо обратить внимание на высокую долю «неопределившихся» по отношению к мигрантам, которая из года в год увеличивается (в 2011 г. таких насчитывалось 69,1 \%, а в 2019 г. - 72,5 \%) [Современный мир... 2019: 190]. Такие высокие цифры свидетельствуют о том, что противоречия есть, но в данный момент они не «актуализированы». В случае заинтересованности националистические объединения могут использовать эту группу молодежи и «раскачивать» национальный вопрос.

Таким образом, несмотря на весьма спокойную ситуацию в области этноконфессиональных отношений в Нижегородской области, на наш взгляд структурам региональной власти необходимо продолжать активно работать, особенно, с молодежью, сосредоточить внимание на профилактике межнациональных отношений.

Необходимым в этой связи видится:

- создание регионального отделения молодежной Ассамблеи народов России. На наш взгляд, эта должна быть дискуссионная площадка, объединяющая молодых участников (представителей этноконфессиональных групп) и «взрослых» экспертов (представителей национально-культурных организаций и диаспор, исследователей ВУЗов и академических институтов, административных структур);

- проведение регулярных и систематических занятий со школьниками и студентами, посвященных вопросам истории, традиций, культуры народов России и вывшего СССР;

- разработка автоматизированной системы мониторинга напряжений и конфликтов на межнациональной и конфессиональной почве.

Статья публикуется при поддержке Школь молодого этнополитолога в Республике Башкортостан (грант Фонда президентских грантов 19-2-022447). 


\section{Список литературы}

Бахлов И.В., Бахлова О.В. 2018. Органы управления государственной национальной политикой субъектов Российской Федерации (на примере Приволжского федерального округа) // Конституционно-правовые проблемы эффективности публичной власти: теория и практика по материалам Всероссийской научно-практической конференции, посвященной 25-летию Конституции Российской Федерации. Поволжский институт управления имени П.А. Столыпина.

Желтов А.А. 2017. Конфессиональный состав населения России С. 5 - 11 // Современные верования и конфессии России. Справочник. Под общей редакцией А.А. Желтова. Вологда.

Морозова Н.М, Устинкин С.В. 2016. Специфика трансформации межнациональных отношений в Нижегородской области // Социология. №3. С.104-112.

Современный мир и молодежь: ценности, риски, угрозы: Монография. Т.1. (Под общ. ред. Д-ра филос. наук, проф. Савруцкой Е.П.). 2019. Н. Новгород: НГЛУ, $268 \mathrm{c}$.

USTINKIN Sergei Vasil'evich, Dr. Sci. (Hist.), Director of the International Cross-Disciplinary Laboratory «The Study of World and Regional Sociopolitical Processes» of Linguistic University of Nizhny Novgorod (31a Minina St., Nizhny Novgorod 603155, Russia), Director of the Volga Branch of the Federal Research Sociological Centre of the Russian Academy of Science (4 Holodny Lane, Nizhny Novgorod 603000, Russia; sv.ustinkin@gmail.com)

MOROZOVA Natalia Mihailovna, Cand.Sci. (Pol. Sci), Associate Professor of the Department of International Relations and World Political Processes, junior researcher of the International Cross-Disciplinary Laboratory «The Study of Global and Regional Sociopolitical Processes» of Linguistic University of Nizhny Novgorod (31a Minina St., Nizhny Novgorod 603155, Russia ), Deputy Director of the Volga branch of the Federal Research Sociological Centre of the Russian Academy of Science (4 Holodny Lane, Nizhny Novgorod 603000, Russia; 4379037@gmail.com)

\section{EVALUATION OF THE ETHNO-CONFESSIONAL RELATIONS MANAGEMENT SYSTEM IN THE NIZHNY NOVGOROD REGION}

\footnotetext{
Abstract. The authors analyze the system of management of interethnic and confessional processes in the Nizhny Novgorod region, assess its effectiveness and identify problems that reduce its effectiveness. Based on the data of sociological studies, the authors come to the conclusion, that due to the comprehensive work of regional authorities, law enforcement agencies, leaders of traditional confessions, diasporas and national communities, society's attitude towards migrants and ethnic groups living in the Nizhny Novgorod region is gradually changing in a positive direction. The article provides recommendations for improving the existing management system.
}

Keywords: ethno-confessional relations, interethnic relations, ethnic group, diaspora, power 